Note

\title{
Study Elucidating Disinfection at Nursery Schools in Ibaraki, Japan
}

\author{
MICHIKO NOHARA ${ }^{1,5}$, TAMIE SUGAWARA ${ }^{2 *}$, JUNKO KURITA $^{3,6}$, NAOMI SAKURAI $^{3}$, \\ MIHO UMEZAWA ${ }^{4}$, NORIKO NAGATA ${ }^{4}$, AND YASUSHI OHKUSA ${ }^{2}$ \\ ${ }^{1}$ Tokyo Kasei University, 1-18-1 Kaga, Itabashi, Tokyo, JAPAN 173-8602, Japan \\ ${ }^{2}$ National Institute of Infectious Diseases, 1-23-1 Toyama, Shinjuku-ku, Tokyo 162-8640, Japan \\ ${ }^{3}$ Center for Medical Sciences, Ibaraki Prefectural University of Health Sciences, \\ 4669-2 Ami, Ami-machi, inashiki-gun, Ibaraki, 300-0394, Japan \\ ${ }^{4}$ Ibaraki Prefectural Institute of Public Health, 993-2 kasahara-cho, Mito-shi, Ibaraki, 310-0852, Japan \\ ${ }^{5}$ Tokyo Women's Medical University, 8-1 Kawada-cho, Shinjuku, Tokyo, 162-8666, Japan \\ ${ }^{6}$ Department of Nursing, Tokiwa University, 1-430-1 Miwa, Mito, Ibaraki, 310-8585, Japan
}

Received 21 January, 2020/Accepted 14 September, 2020

\begin{abstract}
Control of infectious diseases requires switching from usual hygiene such as water wiping and cleaning, to control measures including appropriate and aggressive disinfection using $70 \%$ alcohol and/or hypochlorous acid depending on the pathogen. Nevertheless, some nursery schools might not understand or select proper disinfectant methods. A survey was administered by the local government of Ibaraki prefecture, Japan in January 2018 to all 456 nursery schools in Ibaraki prefecture. The surveyed items were the number of nursery teachers, usual manual hygiene among children, usual disinfection for lavatories, diaper changing spaces, tables used by children for meals, and classroom floors when there was no vomiting in the facilities and no outbreak in surrounding area. Moreover, it asked about disinfection procedures if children vomited during a community outbreak of gastroenteritis infection. We defined proper use for usual disinfection of a lavatory or diaper changing space as chlorine-based disinfectant including hypochlorous acid or $70 \%$ alcohol according to guidelines. Overall, 403 nursery schools responded to the survey. All nursery schools implemented usual hand hygiene. Association between proper disinfection and the size of nursery schools was not significant. Moreover, association between proper disinfection and nursery schools with nurse presence was not found to be significant.
\end{abstract}

Key words : disinfection / nursery schools / 70\% alcohol / chlorine-based disinfectants / gastroenteritis infection.

Control of infectious diseases might require switching from usual hygiene such as water wiping and cleaning, to control measures including appropriate and aggressive disinfection using chlorine-based disinfectants or $70 \%$ alcohol (hereafter, we denote it as just alcohol) depending on the pathogen. Hereafter, "usual" means when there was no vomiting in the facilities and no outbreak in the surrounding area. If some facilities usually disinfect tables, floors, or toys using chlorine-based

*Corresponding author. Tel: +81-3-5285-1111, Fax: +81-35285-1129, E-mail : tammy(a)nih.go.jp disinfectants, it was not only meaningless as control measures, but also it was costly and might be harmful children's or staffs' health.. The guideline published by Ministry of Health, Labour and Welfare, Japan (MHLW) (Guidelines for Infectious Disease Control in Day Nursey schools. 2012 revision) has recommended "To control diffusion of infectious diseases, hand hygiene and proper treatment for excreta or vomit are necessary. Moreover, depending on the situation of outreach of infectious diseases, the facilities should be disinfected appropriately with measures such as increasing the frequency of disinfection." 
So as to control gastroenteritis infection, the guidelines suggest disinfection at the lavatory: Keep it clean by routinely cleaning and disinfecting toilet seats, fouled waste tanks, doors, doorknobs, taps, water supply systems, floors, shelves, and slippers in the lavatory. For doorknobs, handrails, light switches, and other areas, after wiping with water, disinfection using alcohol or chlorine-based disinfectants is recommended. However, appropriate disinfection and cleaning including the use of chlorine-based disinfectants reflecting outbreak situations are necessary for norovirus outbreaks.

For diaper changing spaces, the guideline required that a disposable sheet must be used for diaper changing to avoid contaminating the surrounding area and infection of other children when a child exhibits diarrhea. Similarly with lavatories, nursery schools are asked to use appropriate disinfection and cleaning including the use of chlorine-based disinfectants, reflecting an outbreak situation.

Subjects were 456 nursery schools in Ibaraki prefecture. The survey, administered by the local government of Ibaraki prefecture in January 2018, asked people responsible for (Nursery) School Absenteeism Surveillance System (N)SASSy to answer the following items through web. It contained information about the number of nursery teachers, usual hand hygiene among children, usual disinfection for lavatories, diaper changing spaces, tables used by children for meals, and classroom floors when there was no vomiting or diarrhea in the facilities and no outbreak in the surrounding area. Moreover, the survey asked how respondents disinfect areas if children vomited during an outbreak of gastroenteritis infection ( $\mathrm{Gl}$ ) in the community. If respondents reported that they disinfected those areas, then we also asked them for the classification of their disinfectant, such as whether it was a chlorine-based disinfectant including hypochlorous acid, alcohol, cationic soap, and others.

For these analyses, we disregarded nursery school names. In addition to summary statistics, we analyzed classifications of disinfectants by type of space, which were lavatories, diaper changing spaces, tables for meals, and floors. We tested data by nursery school size: large nursery schools with more than 30 nursery teachers, middle-sized nursery schools with 10 or more nursery teachers but 30 or fewer, and small nursery schools with fewer than 10 nursery teachers. We also analyzed data by the number of nurses in the nursery schools and by presence of nurses at the nursery school. We adjusted data as working hour comparisons with full-time nursery teachers if a facility had some parttime nursery teachers. For example, if one part-time nursery teacher is working for half the duration of a fulltime nursery teacher, then we count that employee as
0.5 nursery teacher employed. The number of children at a facility cannot be used as a size measure because that information is unavailable. Fisher's exact test for 3 by 2 table for "size" and 2 by 2 for "nurse" was adopted as a statistical test. We adopted $5 \%$ as significance level.

We defined proper usual disinfection at tables for meals and floors as unnecessary according to the guideline (Ministry of Health, Labor and Welfare, Guidelines for Infectious Disease Control in Day Nursey schools, 2012 revision, 2012. http://www.mhlw.go.jp/bunya/kodomo/ pdf/hoiku02.pdf). We also defined proper practice for disinfection at the lavatory or diaper changing space two ways as the following: chlorine-based disinfectant including hypochlorous acid, or alcohol in addition to a chlorine-based disinfectant. Since the latter was according to the guideline, we denote it as the "Guideline." Conversely, since the former was our recommendation, we denote it as "Our recommended".

This study was approved by the Ethical Committee of Tokyo Kasei University on July 17, 2019 with approval number Ita2019-3.

In total, 403 nursery schools responded the survey. The response rate was $88.4 \%$. All nursery schools reported implementing usual hand hygiene though it is not shown in tables.

Table 1 shows the answered classification of used disinfectant by space or when children vomited at nursery school. At the lavatory, 392 nursery schools (97.3\%) usually disinfect those areas. The most widely used disinfectant was the chlorine-based disinfectant hypochlorous acid, which was used by $86.8 \%$ of respondents, followed by alcohol. At diaper changing spaces, 375 nursery schools (93.1\%) usually disinfect them; $76.4 \%$ of nursery schools reported using chlorine-based disinfectants including hypochlorous acid, followed by alcohol.

For children's vomiting, 399 nursery schools (99.0\%) disinfected areas, but four respondent nursery schools did not. The most used disinfectant was a chlorine-based disinfectant including hypochlorous acid which was used by $96.8 \%$ of all of nursery schools, followed by alcohol. However, $10.9 \%, 9.9 \%, 11.2 \%$, and $7.7 \%$ of all nursery schools used other disinfectants, respectively, at lavatories, diaper changing spaces, tables for meals, and floors.

By size, all small nursery schools disinfected lavatories. They used alcohol with a higher proportion than nurseries of other sizes. Conversely, large nursery schools used chlorine-based disinfectants including hypochlorous acid with a higher proportion than others. Responses show that $11.5 \%$ of middle-sized nursery schools used other disinfectants.

Table 2 presents the numbers of nursery schools which disinfected properly and their respective proportions 
TABLE 1. Proportions of nursery schools using disinfection and classification of disinfection by space, by case of vomiting, by size, and by nurse presence (\%)

\begin{tabular}{|c|c|c|c|c|c|c|c|}
\hline & & All & Large & $\begin{array}{l}\text { Middle- } \\
\text { sized }\end{array}$ & Small & $\begin{array}{l}\text { More than } \\
\text { one nurse }\end{array}$ & No nurse \\
\hline \multirow{5}{*}{ Lavatory } & Disinfection or not & 97.3 & 94.6 & 97.3 & 100.0 & 97.4 & 97.2 \\
\hline & Chlorine-based disinfectant & 86.8 & 91.9 & 87.0 & 77.8 & 86.8 & 86.9 \\
\hline & $70 \%$ alcohol & 20.8 & 16.2 & 20.1 & 37.0 & 21.7 & 20.1 \\
\hline & Cationic soap & 12.4 & 18.9 & 11.2 & 18.5 & 14.8 & 10.3 \\
\hline & Other & 10.9 & 8.1 & 11.5 & 7.4 & 7.9 & 13.6 \\
\hline \multirow{5}{*}{ Diaper change space } & Disinfection or not & 93.1 & 89.2 & 93.5 & 92.6 & 94.2 & 92.1 \\
\hline & Chlorine-based disinfectant & 76.4 & 86.5 & 77.0 & 55.6 & 74.6 & 78.0 \\
\hline & $70 \%$ alcohol & 25.8 & 18.9 & 26.8 & 22.2 & 24.9 & 26.6 \\
\hline & Cationic soap & 6.9 & 2.7 & 7.4 & 7.4 & 9.0 & 5.1 \\
\hline & Other & 9.9 & 10.8 & 9.7 & 11.1 & 8.5 & 11.2 \\
\hline \multirow{5}{*}{ Table for meals } & Disinfection or not & 88.6 & 86.5 & 88.5 & 92.6 & 88.9 & 88.3 \\
\hline & Chlorine-based disinfectant & 57.8 & 67.6 & 57.2 & 51.9 & 56.6 & 58.9 \\
\hline & $70 \%$ alcohol & 35.5 & 21.6 & 37.5 & 29.6 & 33.3 & 37.4 \\
\hline & Cationic soap & 5.7 & 2.7 & 5.0 & 18.5 & 7.9 & 3.7 \\
\hline & Other & 11.2 & 21.6 & 10.6 & 3.7 & 7.4 & 14.5 \\
\hline \multirow{5}{*}{ Classroom floor } & Disinfection or not & 69.7 & 73.0 & 69.3 & 70.4 & 69.3 & 70.1 \\
\hline & Chlorine-based disinfectant & 59.6 & 62.2 & 59.3 & 59.3 & 58.7 & 60.3 \\
\hline & $70 \%$ alcohol & 9.4 & 8.1 & 9.7 & 7.4 & 8.5 & 10.3 \\
\hline & Cationic soap & 5.0 & 2.7 & 4.4 & 14.8 & 5.8 & 4.2 \\
\hline & Other & 7.7 & 13.5 & 7.7 & 0.0 & 7.4 & 7.9 \\
\hline \multirow{5}{*}{$\begin{array}{l}\text { Child vomiting during } \\
\text { community outbreak }\end{array}$} & Disinfection or not & 99.0 & 97.3 & 99.1 & 100.0 & 98.9 & 99.1 \\
\hline & Chlorine-based disinfectant & 96.8 & 97.3 & 96.8 & 96.3 & 96.8 & 96.7 \\
\hline & $70 \%$ alcohol & 8.9 & 8.1 & 8.8 & 11.1 & 9.5 & 8.4 \\
\hline & Cationic soap & 1.7 & 2.7 & 1.5 & 3.7 & 2.1 & 1.4 \\
\hline & Other & 5.2 & 2.7 & 5.0 & 11.1 & 4.2 & 6.1 \\
\hline
\end{tabular}

Note: In total, there were 403 nursery schools. Size distribution were that 37 were large, 339 were middle-sized, and 27 were small. 189 nursey schools have more than one nurse, but 214 nursey schools did not have any nurse. Large nursery schools were defined as more than 30 nursery teachers. Middle-sized nursery schools were 10 or more, but 30 or fewer nursery teachers. Small nursery schools were defined as having fewer than 10 nursery teachers. Chlorine-based disinfectants include hypochlorous acid. Numbers in the row with "Disinfection or not" were the number and proportion of nursery schools which disinfected the space named in the first column. The following rows with chlorine-based disinfectant, $70 \%$ alcohol, cationic soap, or other show the number and proportion of nursery schools which use the corresponding disinfectant with multiple answers.

TABLE 2. Number of nursery schools and its proportion which use disinfectants properly by space and when children vomit at nursery school

\begin{tabular}{|c|c|c|c|c|}
\hline & \multicolumn{2}{|l|}{ Guideline } & \multicolumn{2}{|l|}{ Our recommended } \\
\hline & Number of nursery schools & $\%$ & Number of nursery schools & $\%$ \\
\hline Lavatory & 302 & 74.94 & 237 & 58.81 \\
\hline Diaper change space & 307 & 74.94 & 217 & 53.85 \\
\hline Tables for meals & 46 & 11.41 & & \\
\hline Classroom floors & 122 & 30.27 & & \\
\hline Child vomiting during ongoing community outbreak & 343 & 85.11 & & \\
\hline
\end{tabular}

Note: We defined proper usual disinfection at tables for meal or floor as unnecessary. Proper disinfectants at lavatories or diaper changing spaces were defined in two ways: chlorine-based disinfectant including hypochlorous acid, and both chlorine-based disinfectant and alcohol. The latter is shown as "Guideline." The former is shown as "Our recommended" in the second row in this table. 
TABLE 3. $p$-values of Fisher's exact tests for proper use of disinfectant by space and when a child vomits at a nursery school by size and nurse presence at the nursery school

\begin{tabular}{|c|c|c|c|c|}
\hline & \multicolumn{2}{|c|}{ Size } & \multicolumn{2}{|c|}{ Nurse } \\
\hline & Guideline & Recommend & Guideline & Recommend \\
\hline Lavatory & 0.944 & 0.242 & 0.421 & 1.000 \\
\hline Diaper changing space & 0.942 & 0.771 & 0.452 & 0.424 \\
\hline Table for meals & \multicolumn{2}{|c|}{0.808} & \multicolumn{2}{|c|}{0.877} \\
\hline Classroom floors & \multicolumn{2}{|c|}{0.950} & \multicolumn{2}{|c|}{0.914} \\
\hline Child vomiting during ongoing community outbreak & \multicolumn{2}{|c|}{0.444} & \multicolumn{2}{|c|}{1.000} \\
\hline
\end{tabular}

Note: "Size" of nursery schools was defined as 30 or more nursery teachers, 10 or more but fewer than 30 nursery teachers, and fewer than 10 nursery teachers. "Nurse" is defined as whether nurses were present in the nursery school. We defined proper usual disinfection at tables for meals and floors as unnecessary. Proper disinfectants at lavatories and diaper changing spaces were defined in two ways: chlorine-based disinfectant including hypochlorous acid only, and both chlorine-based disinfectant and alcohol. The latter is denoted as "Guideline." The former is shown as "Our recommended" in the second row in this table. The statistical procedure was Fisher's exact test for 3 by 2 table for "size" and 2 by 2 for "nurse".

according to definitions of proper use. For lavatory and diaper changing space, although about $75 \%$ of facilities disinfected properly according to "Guideline", they were about 50\% in "Recommend" definition, which suggests that about $25 \%$ of facilities use only alcohol to disinfect these areas.

Table 3 shows $p$-values of Fisher's exact test for sizes of nurse presence and proper disinfection. These results are independent of the definition of proper disinfection for lavatories or diaper changing spaces as "Guideline" and "Our recommended." As presented in Table 3, no significant association was found between proper disinfection practices and nursery school size. Moreover, no significant association was found between proper disinfection and nursery schools with nurse presence.

Results demonstrate that all nursery schools routinely practice hand hygiene irrespective of size or nurse presence. This fact implies that nursery schools at least in Ibaraki prefecture follow healthy practices for their younger children and that those behaviors are conventional.

The guidelines recommend that nursery schools disinfect lavatories and diaper changing spaces using chlorine-based disinfectants or alcohol. Moreover, disinfection is unnecessary but still practiced for tables for meals and floors. In fact, this study revealed that $88.7 \%$ and $70 \%$ of nursery schools routinely disinfected tables for meals and floors, respectively. This fact suggests they did not understand the purpose of disinfection or the situations of outbreaks in surrounding areas. Excessive use of disinfectant might affect health in children or staff, especially chlorine-based disinfectants such as hypochlorous acid. Consequently, appropriate use of disinfectant is best. Based on awareness of outbreak situations in surrounding areas, rapid switching from usual hygiene to disinfection as a protective measure against infectious diseases might promote the proper use of disinfectants.

The "Guideline" definition of proper use for usual disinfection at lavatories or diaper changing spaces was alcohol or chlorine-based disinfectant. However, because children's diarrhea might not be recognized before use of the toilet or changing of diapers, nursery teachers cannot judge whether the diarrhea is infectious or not at that time. Therefore, it is assumed to be difficult to switch quickly from disinfection using alcohol to chlorine-based disinfectant for infection control.

Nurses must also remain mindful of inappropriate use of disinfectants, which damage children's health. For example, nursery teachers sometimes spray alcohol, which might affect the eyes or respiratory health of children. Moreover, spraying alcohol might have uncertain effectiveness, decreased concentration because of added disinfectants, or microbial contamination. Therefore, wiping is recommended over spraying. (CDC. Guideline for Disinfection and Sterilization in Healthcare Facilities, 2008, Ehrenkranz et al.,1980, Rosenberg et al., 1994, Sautter et al., 1984)

Therefore, we presumed the second definition of proper disinfection at lavatories and diaper changing spaces as the "Our recommended" definition. Results based on these two definitions were almost identical: no significant difference was found according to facility size or nurse presence.

Actually, $20.7 \%$ and $12.6 \%$ of nursery schools respectively used alcohol and cationic soap to disinfect lavatories. Moreover, $10.8 \%$ of nursery schools used disinfectants other than chlorine-based disinfectants, alcohol, or cationic soap. They used acidic electrolyzed water, strongly acidic electrolyzed water, or food additive 
preparations based on ethanol for disinfecting cooking utensils. This survey revealed cases in which the nursery schools misunderstood the materials that were actually used. In these cases, their disinfection probably has insufficient effectiveness, even though they believed that they had disinfected areas appropriately. However, because chlorine-based disinfectants including hypochlorous acid cannot be applied to metal, some nursery schools might use both chlorine-based disinfectants and alcohol.

Particularly, when community Gl outbreaks occur and some children vomit at a nursery school, guidelines instruct nurses in details of disinfection: only $1 \%$ of nursery schools did not properly disinfect areas in such cases.

No statistically significant difference was found for size or nurse presence related to recognition of usual hygiene or disinfection. Nursery schools with many nursing teachers or some nurses might more easily host some training courses provided by municipalities or related groups than smaller size nursery schools. Moreover, they might use their nursing expertise more frequently. However, our results contradicted those suppositions. These counterintuitive results might imply that some experience or knowledge gained at training courses might not be shared with non-participating staff at the same nursery school.

\section{ACKNOWLEDGMENTS}

This study received funds from the Comprehensive Research Project, Research Institute of Domestic science, Tokyo Kasei University.

\section{CONFLICT of INTEREST}

No author has any conflict of interest, financial or otherwise, to declare in relation to this study.

\section{REFERENCES}

CDC. (2008) Guideline for Disinfection and Sterilization in Healthcare Facilities.

Ehrenkranz NJ, Bolyard EA, Wiener M, Cleary TJ. (1980) Antibiotic-sensitive Serratia marcescens infections complicating cardiopulmonary operations: contaminated disinfectant as a reservoir. Lancet, 2, 1289-1292.

Guidelines for Infectious Disease Control in Day Nursey schools, 2012 revision Ministry of Health, Labor and Welfare November 2012. http://www.mhlw.go.jp/bunya/kodomo/ pdf/hoiku02.pdf

Rosenberg N, Baud F, Gervais P. (1994) Persistent asthma after inhalation of a mixture of sodium hypochlorite and hydrochloric acid. Chest ,105, 1895-6.

Sautter RL, Mattman LH, Legaspi RC. (1984) Serratia marcescens meningitis associated with a contaminated benzalkonium chloride solution. Infection control, $\mathbf{5}$, 223-225. 